\title{
GENDER DIFFERENCES IN RISK AVERSION AND AMBIGUITY AVERSION
}

\author{
Lex Borghans \\ Maastricht University \\ James J. Heckman \\ University of Chicago
}

\author{
Bart H. H. Golsteyn \\ Maastricht University \\ Huub Meijers \\ Maastricht University
}

\begin{abstract}
This paper demonstrates gender differences in risk aversion and ambiguity aversion. It also contributes to a growing literature relating economic preference parameters to psychological measures by asking whether variations in preference parameters among persons, and in particular across genders, can be accounted for by differences in personality traits and traits of cognition. Women are more risk-averse than men. Over an initial range, women require no further compensation for the introduction of ambiguity but men do. At greater levels of ambiguity, women have the same marginal distaste for increased ambiguity as men. Psychological variables account for some of the interpersonal variation in risk aversion. They explain none of the differences in ambiguity. (JEL: J24, D03, D80)
\end{abstract}

\section{Introduction}

A classic study by Ellsberg (1961) found that people place higher values on bets with known probabilities (risk) than bets with unknown probabilities (uncertainty). He termed this preference ambiguity aversion. Ambiguity aversion has been used to rationalize the equity-premium puzzle and to explain why people act differently in complex situations (Seo 2008). Hansen (2005, 2007) establishes conditions under which the prices of risky and uncertain choices depend separately on risk aversion parameters and ambiguity aversion (model uncertainty

\footnotetext{
Acknowledgments: This paper has benefited from comments by Steffen Altmann, Peter Broer, Liam Delaney, Thomas Dohmen, Angela Lee Duckworth, Katharina Marie Eckartz, Philipp Eisenhauer, Armin Falk, Helga Fehr-Duda, Lars Peter Hansen, Michael Hurd, Erin Krupka, John List, Peter Neary, Friedhelm Pfeiffer, Phil Reny, Arthur van Soest, Harald Uhlig, Terry Vaughn, the editor, an anonymous referee, and participants of the 2008 ESSLE, 2008 IZA Behavioral Workshop, 2008 EEA conference, the Conference on Understanding Economic Decision-making in Jackson Hole, and a seminar at CPB in The Hague. We thank Stella Maris High School for support in the organization of the experiment. The research was financed partly by Golsteyn's Meteor research grant M.08.5217. Golsteyn thanks IZA, where he stayed during this research, for its hospitality.

E-mail addresses: Borghans: lex.borghans@ algec.unimaas.nl; Golsteyn: b.golsteyn@ algec.unimaas. nl; Heckman: jjh@uchicago.edu; Meijers: huub.meijers@merit.unimaas.nl
} 
aversion) parameters. Unresolved in this literature is whether risk and ambiguity aversion are empirically distinct aspects of preferences, i.e. if there are distinct ambiguity and risk aversion parameters.

This paper shows that in real-world choices, the two parameters are distinct and that they differ across genders. Supporting the two distinct roles played by these parameters, differences across people in risk aversion, but not ambiguity aversion, can be related to standard psychological measurements. This paper contributes to an emerging literature surveyed in Borghans et al. (2008) that relates economic preference parameters to psychological measurements. From a baseline risky situation, we link valuations of bets to cognitive and noncognitive personality traits: IQ, the Big Five (openness, conscientiousness, extraversion, agreeableness, neuroticism), grit (ambition), self-control, and flexible thinking.

Using Halevy's (2007) version of Ellsberg's measure of ambiguity aversion, we investigate how the willingness to pay for lotteries changes when the degree of ambiguity is varied. Ambiguity aversion is studied by presenting participants in an experiment with urns containing 10 balls which can be either blue or yellow. In some urns, the composition of blue and yellow balls is known. In other urns, the composition is not known. Participants bet on a color and give a minimum price at which they would sell the bet.

For men and women separately, we study risk aversion and changes in measured ambiguity aversion when the degree of ambiguity is increased. We analyze whether cognitive and noncognitive factors explain differences in risk and ambiguity aversion between men and women.

Our experiment is conducted on a sample of 347 15- and 16-year-old students at a Dutch high school. Only a fraction of them continue their education to the university level. The sample population studied offers a wider dispersion of traits than does the sample of university students analyzed by Halevy (2007). A unique feature of our experiment is that participation was compulsory. We also know who among our sample would have voluntarily participated because we initially sought volunteers, and the final sample includes the initial sample of volunteers.

Women are more risk-averse than men. Over an initial range, men reduce their valuation of ambiguous urns more than women. After that, men and women equally value marginal changes in ambiguity. To the best of our knowledge, these findings are novel. Because psychological measures are related to risk but not to ambiguity, risk aversion and ambiguity aversion are distinct traits. They depend on different variables.

Our evidence provides fresh insight into the relationship between psychological traits and economic preference parameters. There is much evidence that women are more risk-averse than men (see, e.g., Hartog, Ferrer-i-Carbonell and Jonker 2002; Agnew et al. 2008). With respect to ambiguity aversion, Schubert et al. (2000) find that women are more ambiguity-averse than men in an investment 
context but not in an insurance context. ${ }^{1}$ Powell and Ansic (1997) report that women are more risk-averse and ambiguity-averse. Dohmen et al. (2008) find that lower cognitive ability and less openness to new experiences predict greater risk aversion. Benjamin, Brown, and Shapiro (2006) report that small-stakes risk aversion and short-run time preference are inversely related to achievement test scores. Borghans et al. (2008) review this literature.

This paper is organized in the following way. Section 2 describes the experimental procedure. Section 3 discusses the empirical results. Section 4 concludes.

\section{Experimental Design and Procedure}

\subsection{Structure of the Experiment}

In our experiment, students were presented with different urns each containing 10 balls which could be either blue or yellow. They were asked to bet on a color and value each of these urns, considering that one ball will be drawn and that they will receive $€ 2$ if they guess the right color.

We used four urns that differed gradually in their degree of ambiguity, labeled urn 1 , urn 2 , urn 3 , and urn 4 , respectively. The urns are presented in randomized order to the participants. After the students value the urns, a uniform random number is drawn to locate which of the urns is used for payment. In a second round we repeat the same menu of choices. We use average scores over both rounds in our analysis.

Urn 1 is the case with only risk and is described as: "There is an urn with 5 blue and 5 yellow balls. At random, one ball will be drawn from this urn. If you guess the right color, you'll earn $€ 2$. If you are wrong, you'll get nothing." In urn 2 we introduce some ambiguity: "There is an urn with 10 blue and yellow balls, but the number of yellow and blue balls is unknown. It can be anything between 4 and 6 blue balls and 4 and 6 yellow balls. At random, one ball will be drawn from this urn. If you guess the right color, you'll earn $€ 2$. If you are wrong, you'll get nothing." In urn 3 ambiguity is further increased varying the number of blue and yellow balls between 2 and 8: "There is an urn with 10 blue and yellow balls, but the number of yellow and blue balls is unknown. It can be anything between 2 and 8 blue balls and 2 and 8 yellow balls. At random, one ball will be drawn from this urn. If you guess the right color, you'll earn $€ 2$. If you are wrong, you'll get nothing." In urn 4 ambiguity is further increased by varying the number of blue and yellow balls between 0 and 10: "There is an urn with 10

1. However, contrary to a large literature, Schubert et al. (1999) report no gender difference in risk aversion when decisions are made in an insurance or investment context. They do find that women are more risk-averse in abstract gambling decisions. 
blue and yellow balls, but the number of yellow and blue balls is unknown. It can be anything between 0 and 10 blue balls and 0 and 10 yellow balls. At random, one ball will be drawn from this urn. If you guess the right color, you'll earn $€ 2$. If you are wrong, you'll get nothing." Urns 1 (risk) and 4 (uncertainty) represent the classic Ellsberg questions. Urns 2 and 3 are added to analyze how reservation prices change in response to changes in ambiguity.

For each urn, students are asked to bet on a color and to give the minimum price at which they would be willing to sell the bet. If an urn is selected for actual payment, a computer generates a random offer between 0 and 200 eurocents. If the offer is higher than the reservation price set by the participant, the bet is automatically sold and the participant gains the money the computer offered. If the offer is lower than the reservation price, the lottery is actually carried out by spinning a wheel similar to a pie-chart that indicates the distribution of yellow and blue balls. In the case of ambiguous urns, ambiguity is resolved when the pie-chart is revealed. When the wheel of the selected pie-chart stops spinning, the participants can see whether the arrow points at a blue or a yellow ball.

Before the experiment begins, subjects are given an interactive tutorial to educate them on how to set reservation prices. In the tutorial, they are asked to set the reservation price for a $€ 1$ coin. If they set the reservation price higher than 101 eurocents or below 100 eurocents they are instructed that they make a loss using that strategy. For students who set the wrong reservation price, the questions and explanation are repeated. ${ }^{2}$ The tutorial ends with two hypothetical Ellsberg questions.

\subsection{IQ and Psychological Traits}

We collect several measures of IQ and personality. In this paper we use 8 Raven Progressive Matrices to measure IQ; 50 items to measure the Big Five (openness, conscientiousness, extraversion, agreeableness, neuroticism) from Goldberg (1992); 5 questions to measure ambition from Duckworth et al.'s (2007) Gritscale; 10 items from the Self-Control Act-Frequency Measure (Duckworth 2008); and 10 items from the Stanovich and West (1997) Flexible Thinking Scale.

We also obtained scores on an achievement test (CITO) taken at age 12, and scores on the Differential Aptitude Test, another achievement test. Except for the flexible thinking indicator, all measured traits have high Cronbach's alphas, a measure of inter-correlation among scores. People with high IQs are less extraverted, have more self-control, are able to think more flexibly, make fewer cognitive mistakes, and have lower rates of time preference.

2. A working paper shows that students who score high on flexible thinking and the Raven test set wrong reservation prices less often in this tutorial. Agreeable and extraverted students set wrong reservation prices more often (Borghans et al. 2009). 


\subsection{Procedures}

Our subjects attend a high school near Maastricht in the Netherlands. This school educates diverse students who will attain different levels of education. There is more diversity in our sample than in the samples of university students widely used in the literature. There are three academic tracks. We exclude students from the lowest track. The middle track is vocational. The upper track is collegiate.

Participation was compulsory. The students in our samples are 15 and 16 years of age. Some of the students had valid reasons not to participate. Of an initial sample of 374 students, 347 students (93.1\%) actually participated. A unique feature of the data is that we also know who would have participated in the event there were voluntary participation because we initially sought volunteers (52 students volunteered).

Most students finished the experiment within 1.5 hours. The maximum time spent was almost 2 hours. On average, they earned $€ 21.30$ with a minimum of $€ 8.20$ and a maximum of $€ 36.60$. In the Netherlands, a normal wage for a 16year-old person is around $€ 3$ per hour. Most students in this age group do not work and receive on average $€ 20$ per month as pocket money (NIBUD, 2005). Thus the amounts earned by participants were relatively high compared to their alternative wages. The money was paid in cash after students finished the experiment. During the experiment, students were notified of their cumulative earnings after each spin of the Ellsberg wheel.

\section{Results}

Table 1 reports the reservation prices averaged over rounds 1 and 2 that respondents give for urns 1 and $4 .{ }^{3}$ The difference in the valuation of urns 1 and 4 is a measure of ambiguity aversion. On average, students are ambiguity-averse. The reservation price of urn 1 is 12.4 cents higher than that of urn 4 ( $p$-value $=0.000)$. This supports the analysis of Hansen that ambiguity (model uncertainty) lowers the value of a choice distinct from any effect arising from risk aversion. ${ }^{4}$

3. There is no statistically significant difference between the scores on round 1 and 2 . See Borghans et al. (2009).

4. Separately analyzing the people who volunteered and those who did not, risk aversion is greater for the volunteers while ambiguity aversion is somewhat lower. This suggests that the people who sort into experiments are less fearful of uncertainty. However, these differences are not statistically significant. The standard deviation of reservation prices is lower for the volunteers (the difference is statistically significant for urns 3 and 4), especially for the answers of volunteers who are in the collegiate track. For this group the difference is statistically significant for urns 1,3 , and 4 . See Borghans et al. (2009). 


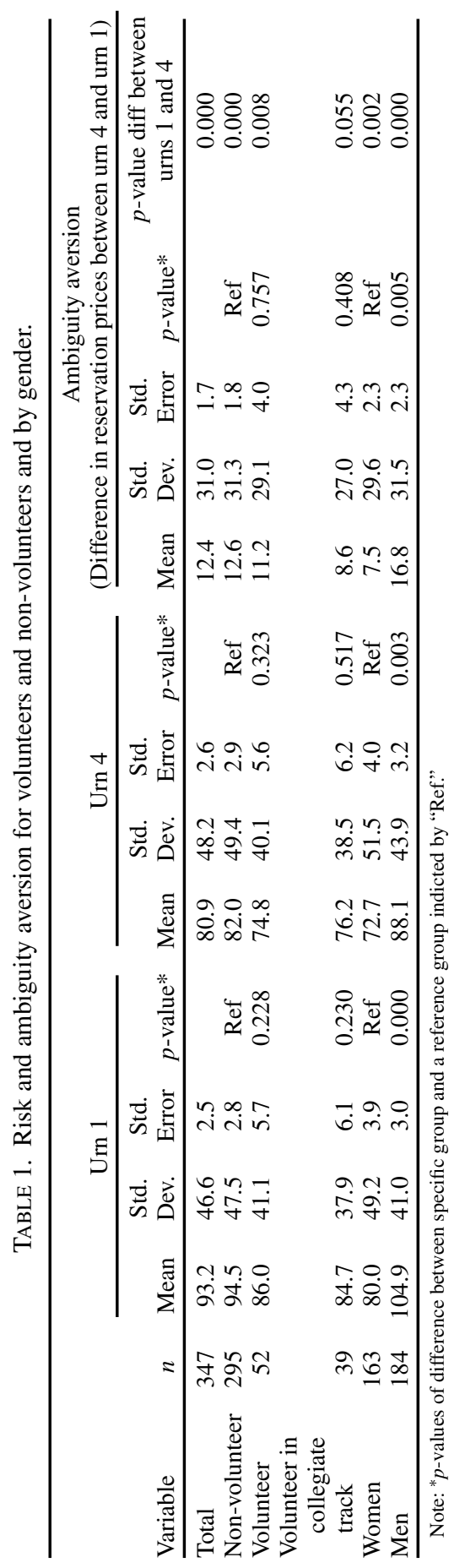




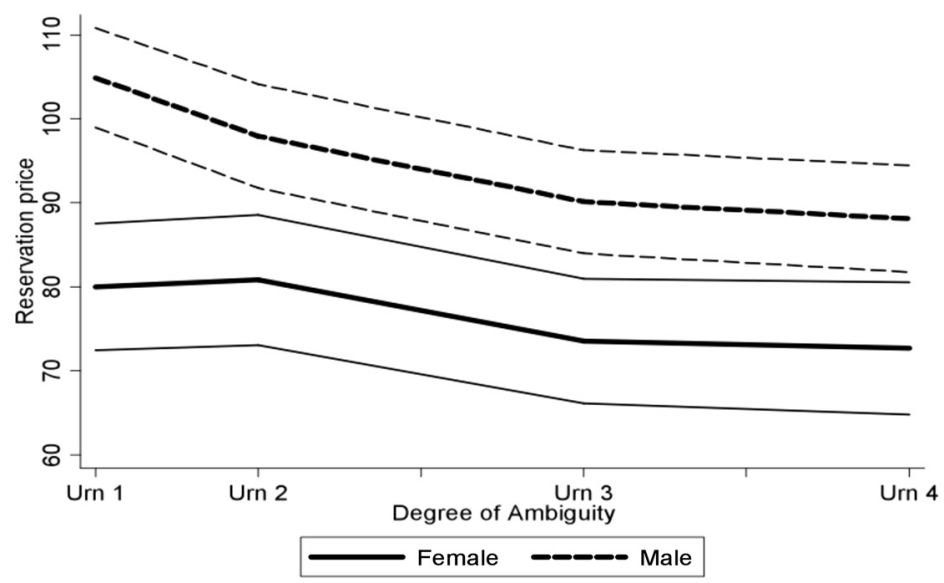

FIGURE 1. Varying the degree of ambiguity, women versus men (5\% confidence interval bands around relationships).

Men have much higher reservation prices for urn 1 than women so they are less risk-averse than women. However, men display more ambiguity aversion than women in the sense that the difference in reservation prices between urn 1 and urn 4 is larger for men than for women.

Figure 1 plots the changes in the reservation price when the degree of ambiguity is successively increased in the lotteries. For men, the reservation price decreases sharply when ambiguity increases from urn 1 (no ambiguity) to urn 2 (moderate ambiguity: 4-6 balls). For women, there is no change in the reservation price moving from urn 1 to urn 2 . When ambiguity increases further (urn 3: 2-8 balls and urn 4: 0-10 balls), the decrease in value of the lottery for men is similar to the decrease for women. The gap in reservation prices remains the same for urns 3 and 4. Men and women price marginal increases of ambiguity in the same way.

One potential explanation for gender differences is that risk and ambiguity are related to cognitive and noncognitive traits on which men and women differ. Table 2 reports the empirical relationship between the reservation prices of the risky urn and the difference between the ambiguous urns and the risky urn as dependent variables, and the Raven IQ and personality traits as independent variables. The value of the risky urn is affected by personality traits whereas the difference between ambiguous urns and the risky urn is not. People who are less agreeable, less neurotic, and who have more ambition are less risk-averse (i.e., set a higher reservation price for urn 1). The comparison with the highest ambiguity (urn 4-urn 1) has approximately half the $R^{2}$ of the model for urn 1. This difference is larger for women than for men. None of the psychological traits is associated with differences in ambiguity aversion (see $F$-test 


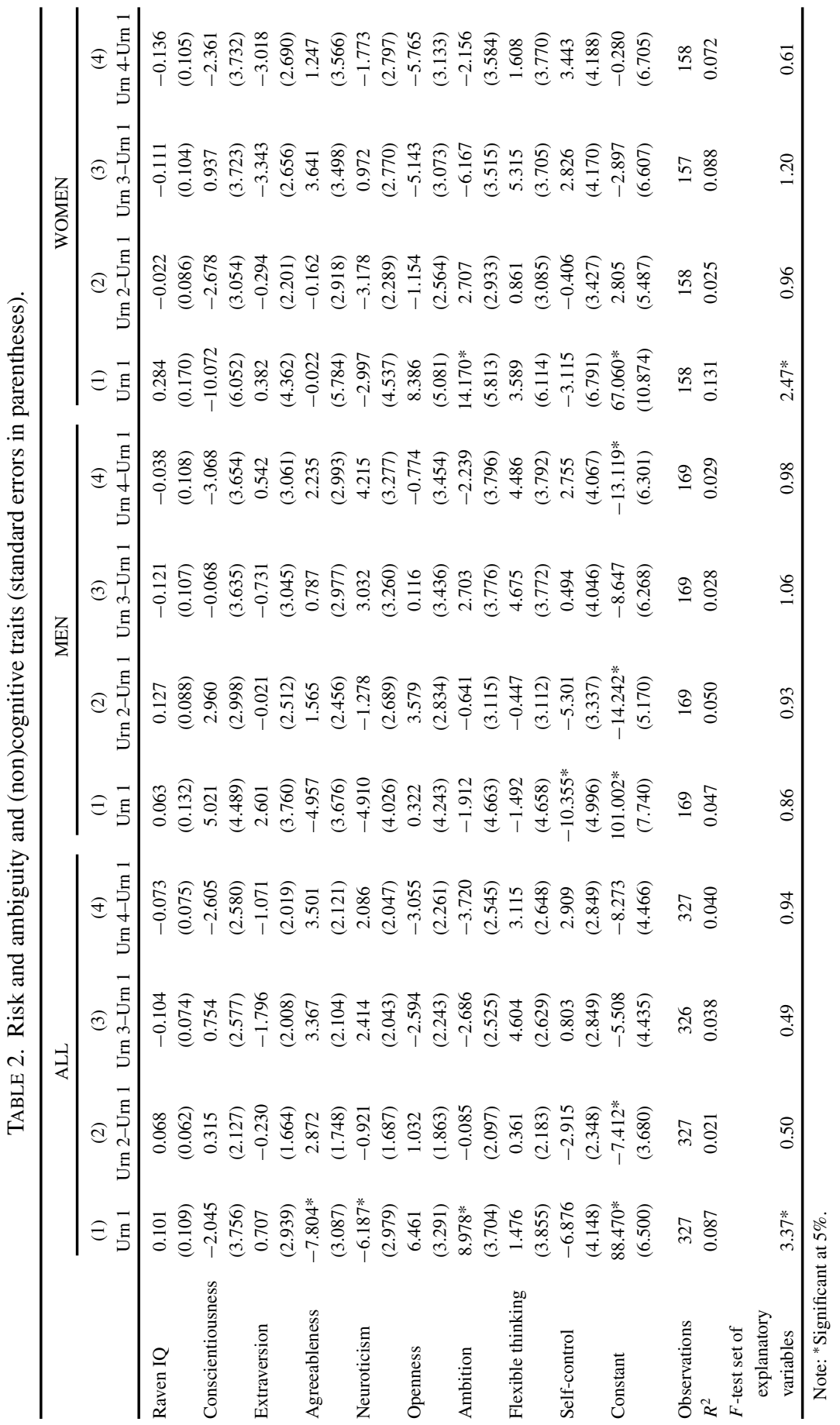




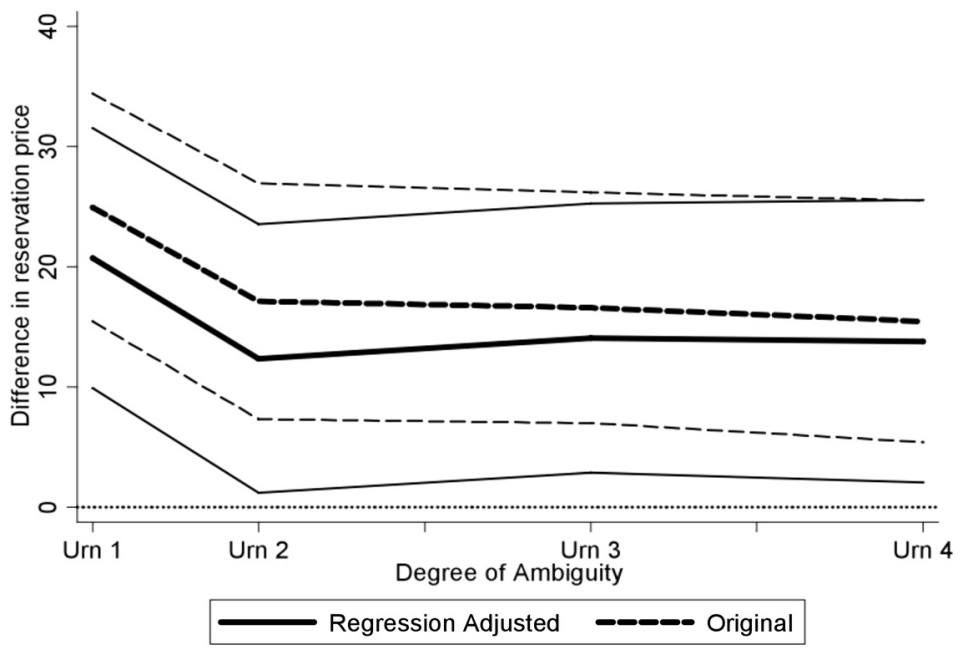

FIGURE 2. Difference between male and female reservation prices, controlling for IQ and personality traits (5\% confidence interval bands around relationships).

at the base of the table). This evidence is consistent with the existence of two distinct preference parameters. Separating the analysis for men and women, we find that women who have more ambition are less risk-averse. Men who have more self-control are more risk-averse. Adjusting for psychological traits explains little of the gender difference in risk aversion or ambiguity aversion (see Figure 2).

\section{Conclusions}

This paper analyzes gender differences in risk aversion and ambiguity aversion. Using Halevy's (2007) measure of ambiguity aversion, we investigate how the willingness to pay increases when the degree of ambiguity is reduced. We analyze the extent to which differences in the evaluations of risk and ambiguity are related to cognitive and personality traits.

Our analysis confirms findings from a previous literature that women are more risk-averse than men. Women initially respond to ambiguity much more favorably than men (i.e., their reservation price does not decline), but as ambiguity increases, men and women show similar marginal valuations of ambiguity. Psychological traits are strongly associated with risk but not with ambiguity. Adjusting for psychological traits explains a small portion of the gender difference in risk aversion but none of the difference in ambiguity aversion. 


\section{References}

Agnew, Julie R., Lisa R. Anderson, Jeffrey R. Gerlach, and Lisa R. Szykman (2008). "Who Chooses Annuities? An Experimental Investigation of the Role of Gender, Framing, and Defaults." American Economic Review, 98, 418-442.

Benjamin, Daniel J., Sebastian A. Brown, and Jesse M. Shapiro (2006). "Who is 'Behavioral'? Cognitive Ability and Anomalous Preference.” Working paper, Cornell University.

Borghans, Lex, Angela L. Duckworth, James J. Heckman, and Bas ter Weel (2008). "The Economics and Psychology of Personality Traits.” Journal of Human Resources, 43, 972 1059.

Borghans, Lex, Bart H. H. Golsteyn, James J. Heckman, and Huub Meijers (2009). "Gender Differences in Risk Aversion and Ambiguity Aversion.” NBER Working Paper w14713.

Dohmen, Thomas, Armin Falk, David Huffman, and Uwe Sunde (2008). "Are Risk Aversion and Impatience Related to Cognitive Ability?” IZA Discussion Paper No. 2735.

Duckworth, Angela L. (2008). The Self-Control Act-Frequency Scale. Working paper, University of Pennsylvania.

Duckworth, Angela L., Chistopher Peterson, Michael D. Matthews, and Dennis R. Kelly (2007). "Grit: Perseverance and Passion for Long-Term Goals." Journal of Personality and Social Psychology, 92, 1087-1101.

Ellsberg, Daniel (1961). "Risk, Ambiguity, and the Savage Axioms." Quarterly Journal of Economics, 75, 643-669.

Goldberg, Lewis R. (1992). "The Development of Markers for the Big-Five Factor Structure.” Psychological Assessment, 4, 26-42.

Halevy, Yoram (2007). "Ellsberg Revisited: An Experimental Study." Econometrica, 75, 503536.

Hansen, Lars Peter (2005). "Comment: On Exotic Preferences for Macroeconomics, By D. K. Backus, B. R. Routledge and S. E. Zin.” NBER Macroeconomics Annual 2004, edited by M. Gertler and K. Rogoff.

Hansen, Lars Peter (2007). "Beliefs, Doubts and Learning: Valuing Macroeconomic Risk; Richard T. Ely Lecture." American Economic Review, 97, 1-30.

Hartog, Joop, Ada Ferrer-i-Carbonell, Nicole Jonker (2002). "Linking Measured Risk Aversion to Individual Characteristics." Kyklos, 55, 3-26.

NIBUD (2005). "NIBUD, Nationaal Scholierenonderzoek 2004/2005 Een onderzoek naar inkomsten, uitgaven, baantjes en omgaan met geld." NIBUD, Utrecht.

Powell, Melanie, and David Ansic (1997). "Gender Differences in Risk Behaviour in Financial Decision-Making: An Experimental Analysis.” Journal of Economic Psychology, 18, 605 628.

Schubert, Renate, Matthias Gysler, Martin Brown, and Hans-Wolfgang Brachinger (1999). "Financial Decision-Making: Are Women Really More Risk-Averse?" American Economic Review, 89, 381-385.

Schubert, Renate, Matthias Gysler, Martin Brown, and Hans-Wolfgang Brachinger (2000). "Gender Specific Attitudes Towards Risk and Ambiguity: An Experimental Investigation." Unpublished manuscript, ETH Zurich.

Seo, Kyoungwon (2008). "Ambiguity and Second-Order Belief." Unpublished manuscript, University of Rochester.

Stanovich, Keith E., and Richard F. West (1997). "Reasoning Independently of Prior Belief and Individual Differences in Actively Open-Minded Thinking." Journal of Educational Psychology, 89, 342-357. 